\section{Epidemiologia da leishmaniose tegumentar americana no Estado do Acre, Amazônia brasileira}

\author{
Epidemiology of American tegumentary leishmaniasis \\ in the State of Acre, Brazilian Amazon
}

\begin{abstract}
This was a descriptive statistical study of 8,516 cases of American tegumentary leishmaniasis in the State of Acre, Brazil, from 2001 to 2006 (second period), comparing the results to a previous publication with data from the same State for 1992 to 1997 (first period). Prevalence in the State more than doubled (55.7/10,000 inhabitants from 1992 to 1997 and 128.5/10,000 inhabitants from 2001 to 2006). Males predominated (68.8\%, $n=5,860$ ) in the second period. Mean age in the second period was 26.3 years, slightly lower than in the first. Individuals with low schooling were more affected by the disease. The other variables were area of residence, occupation, diagnostic criterion, clinical form, treatment, relapse, time before seeking treatment, and evolution. In conclusion, American tegumentary leishmaniasis epidemiological indicators worsened in the State between the two periods.
\end{abstract}

Leishmaniasis; Residence Characteristics; Amazonian Ecosystem
Natal Santos da Silva 1

Vitor Dantas Muniz 2

\section{Introdução}

A leishmaniose tegumentar americana é uma zoonose presente em todos os estados brasileiros (Sistema de Informação de Agravos de Notificação. http://dtr2004.saude.gov.br/sinanweb/novo/, acessado em 01/Fev/2008). Causada por protozoário do gênero Leishmania e transmitida pela picada de diferentes espécies de flebotomíneos infectados. Pode acometer o ser humano no momento em que este participa acidentalmente do ciclo silvestre de manutenção da doença, por meio de atividades que necessitem de sua entrada no ambiente de mata ou mesmo devido à existência de moradias localizadas perigosamente próximas à borda da floresta ou até mesmo no interior da mesma. Contudo, atualmente há cada vez mais evidências da transmissão peridomiciliar, por sugestiva adaptação do vetor ao redor das residências $1,2,3,4,5,6,7,8,9$, como conseqüência das modificações no meio ambiente pelo homem, levando à migração de algumas espécies de Leishmania e de seus vetores para as imediações dos domicílios 10, mesmo em áreas mais urbanizadas 11,12 .

Segundo o Ministério da Saúde do Brasil, somente no ano de 2006 foram notificados 25.782 casos de leishmaniose tegumentar americana no país, dos quais 14.900 registraram-se nos estados que fazem parte da Amazônia brasileira, mantendo-se valores semelhantes em anos anteriores (Sistema de Informação de Agravos de Noti- 
ficação. http://dtr2004.saude.gov.br/sinanweb/ novo/, acessado em 01/Fev/2008). Denotando assim, característica de doença endêmica nacional. Apesar disso, ela faz parte das doenças negligenciadas.

A importância de melhor entendimento epidemiológico da leishmaniose tegumentar americana consiste não somente no fato de possuir ampla distribuição geográfica no país, mas também devido à constatação de que formas que podem levar a lesões permanentes tendem a acarretar graves comprometimentos psicossociais no indivíduo afetado. Entendê-la globalmente é fundamental para adotar medidas que possam minimizar a sua incidência e, conseqüentemente, o sofrimento daqueles que convivem com essa zoonose.

No Estado do Acre, tem-se poucos estudos referentes à situação da leishmaniose tegumentar americana em seu território. Os únicos dados disponíveis na literatura referem-se a uma publicação de 1999 13. O presente trabalho tem o objetivo de atualizar os dados epidemiológicos dessa doença no referido estado e confrontar com resultados apresentados em momentos diferentes de outro estudo publicado 13 .

\section{Materiais e métodos}

\section{O Estado do Acre}

O Estado do Acre possui uma superfície total de $152.581,39 \mathrm{~km}^{2}$, com altitude média de $200 \mathrm{~m}$. Faz fronteira ao norte com o Estado do Amazonas, ao leste com o Estado de Rondônia, ao sudeste com a Bolívia e ao sul e oeste com o Peru. Possui clima equatorial e vegetação caracterizada como floresta tropical úmida. Em 2006, a população estimada era de 686.652 habitantes (Instituto Brasileiro de Geografia e Estatística. http://www. ibge.gov.br, acessado em 03/Fev/2008). O estado é composto por duas mesorregiões, os vales do Acre e do Juruá, cinco microrregiões e 22 municípios.

O Vale do Acre, com população estimada em 488.751 habitantes (Instituto Brasileiro de Geografia e Estatística. http://www.ibge.gov.br, acessado em 03/Fev/2008) no ano de 2006, é composto pelas microrregiões de Sena Madureira, Rio Branco e Brasiléia. A primeira é formada pelos municípios de Sena Madureira, Santa Rosa do Purus e Manoel Urbano. A segunda pelos municípios de Rio Branco (capital do estado), Acrelândia, Bujari, Capixaba, Plácido de Castro, Porto Acre e Senador Guiomard. A última pelos municípios de Brasiléia, Assis Brasil, Epitaciolândia e Xapuri 14.
Em 2006, o Vale do Juruá possuía população estimada em 197.901 habitantes (Instituto Brasileiro de Geografia e Estatística. http://www. ibge.gov.br, acessado em 03/Fev/2008). É formado pelas microrregiões de Cruzeiro do Sul e de Tarauacá. A primeira é constituída pelos municípios de Cruzeiro do Sul, Mâncio Lima, Marechal Thaumaturgo, Porto Walter e Rodrigues Alves. A segunda, pelos municípios de Tarauacá, Feijó e Jordão 14 .

\section{Dados do estudo}

Foram coletados todos os registros de leishmaniose tegumentar americana notificados entre os anos de 2001 e 2006 no estado pelo Departamento de Ações Básicas em Saúde (DABS), pertencente à Secretaria de Saúde do Estado do Acre, o qual é o órgão responsável pelo sistema de informação e controle de doenças de notificação no estado.

As variáveis avaliadas foram: local da notificação, sexo, idade, escolaridade, zona de residência, ocupação, critério de diagnóstico, forma clínica, tratamento, recidiva, tempo para procurar tratamento e evolução da doença. Agruparam-se as ocupações em três categorias: rural (como pecuarista, agricultor, pescador, índio, seringueiro e peão), não-rural (médico, enfermeiro, funcionário público, militar, engenheiro, entre outras) e não-determinadas (doméstica, aposentado, menor de idade e estudante).

\section{Análise estatística}

Devido ao fato de os dados analisados serem censitários, realizou-se um estudo estatístico descritivo das variáveis selecionadas. Para isso, fez-se uso do programa SPSS 13.0 (SPSS Inc., Chicago, Estados Unidos).

Para o cálculo da prevalência, utilizou-se a população no final de cada ano do período. A fim de que isso fosse possível, adotou-se o método de interpolação linear para calcular a população no final de cada ano, tendo em vista que a população anual é estimada no meio do ano pelo Instituto Brasileiro de Geografia e Estatística (http:/ /www. ibge.gov.br, acessado em 03/Fev/2008). Lançouse mão dessa ferramenta estatística devido ao fato de que os casos de leishmaniose tegumentar americana foram computados no final de cada ano e, desta forma, haverá compatibilidade entre os dois valores.

Foram utilizados alguns resultados de publicação anterior 13 com a finalidade de comparar estatisticamente momentos diferentes sobre a epidemiologia da leishmaniose tegumentar americana no Acre entre 1992 e 1997 (primeiro 
período) e este trabalho que corresponde aos dados entre 2001 e 2006 (segundo período). Apresentando intervalo de quatro anos entre os dois estudos e seis anos de estudo em cada trabalho.

\section{Resultados}

Foram notificados 8.516 casos de leishmaniose tegumentar americana no estado no período de 2001 a 2006. Desse total, 7.746 (91\%) correspondem aos casos novos, 650 (7,6\%) equivalem às recidivas e 120 (1,4\%) os ignorados. A prevalência no estado mais que dobrou ao se comparar os dois períodos: 55,7/10 mil habitantes de 1992 a 1997 e 128,5/10 mil habitantes entre 2001 e 2006. Contudo, ao observar ano a ano os dois períodos, verificou-se que no primeiro período a prevalência apresentou grandes flutuações a cada ano, enquanto que no segundo, embora tenha maiores valores, apresentou queda acentuada na curva de prevalência a partir de 2004 (Figura 1).

O Vale do Acre contribuiu com o maior número de casos notificados $(87,3 \% ; \mathrm{n}=7.434)$ e maior prevalência no segundo período (158,2/10 mil habitantes) quando comparado com o Vale do Juruá (55,7/10 mil habitantes). Nas duas mesorregiões houve aumento em suas prevalências em relação ao período de 1992 a 1997 (Tabela 1). A microrregião de Brasiléia continua sendo a maior contribuinte do Vale do Acre para a elevada prevalência, sobretudo no segundo período (443,3/10 mil habitantes para o primeiro período e 231,8/10 mil habitantes para o segundo) (Tabela 1). Dentro da microrregião de Brasiléia, o Município de Xapuri ainda representa o principal foco de leishmaniose com 639,6/10 mil habitantes no segundo período, com elevação da prevalência em relação ao período anterior (501,7/10 mil habitantes). A microrregião de Sena Madureira destaca-se por ter apresentado a segunda maior prevalência entre os anos de 2001 e 2006 (311,4/10 mil habitantes). Entre os anos de $1992 \mathrm{e}$ 1997 nessa mesma microrregião, totalizaram-se 80,4 casos para 10 mil habitantes. A microrregião com menor prevalência no período permaneceu sendo a de Cruzeiro do Sul (53/10 mil habitantes) em comparação com o primeiro período (25/10 mil habitantes), porém, com quase duas vezes mais casos. O Município de Rodrigues Alves apresentou a menor prevalência entre $2001 \mathrm{e}$ 2006 (20/10 mil habitantes).

Foram registrados $5.860(68,8 \%)$ casos de leishmaniose tegumentar americana no estudo entre os homens; valores abaixo do observado entre os anos de 1992 e 1997, os quais apresentaram $71 \%$ dos homens sendo acometidos. Entre todas as microrregiões, na de Brasiléia obteve-se o maior número de casos entre mulheres (41\%; $\mathrm{n}=949$ ) no período de 2001 a 2006. Sendo que dentro dessa microrregião o Município de Xapuri foi o que mais contribuiu para isso, apresentando $46,3 \%(n=418)$ dos casos no sexo feminino entre 2001 e 2006.

A análise das idades dos pacientes mostrou que no Estado do Acre, no período de 2001 a 2006, o primeiro quartil (Q1) foi igual a 13 anos, mediana (Md) de 23,1 anos, a média aritmética $(\mu)$ de 26,3 anos, desvio-padrão $(\sigma)$ de 17,5 anos e coeficiente de variação $\left(C_{v}\right)$ igual a $66,7 \%$. Valores discretamente menores daqueles apresentados no período anterior $(\mathrm{Q} 1=15$ anos; $\mathrm{Md}=$ 24 anos; $\mu=27,4$ anos; $\sigma=17,5$ anos; $C_{\nu}=63 \%$ ). A Figura 2 evidencia a clara assimetria positiva, notoriamente populações mais jovens. Tanto o Vale do Acre quanto o do Juruá caracterizaramse por apresentar valores semelhantes em relação às idades dos pacientes $(\mathrm{Q} 1=13$ anos, $\mathrm{Md}=$ 22 anos, $\mu=26$ anos, $\sigma=17,6$ anos, $C_{\nu}=67,7 \%$ e Q1 = 16 anos, $\mathrm{Md}=24$ anos, $\mu=27,8$ anos, $\sigma=$ 16,7 anos; $C_{v}=60,2 \%$, respectivamente). As duas microrregiões que tiveram as menores faixas etárias acometidas pela leishmaniose tegumentar americana foram Sena Madureira $(\mathrm{Q} 1=11$ anos, $\mathrm{Md}=20$ anos, $\mu=23,9$ anos, $\sigma=17,4$ anos, $C_{\nu}=$ $72,7 \%)$ e Brasiléia ( $\mathrm{Q} 1=10$ anos, $\mathrm{Md}=18$ anos, $\mu=22,1$ anos, $\sigma=16,2$ anos, $C_{v}=73,3 \%$ ). Nessa última microrregião o município com menores índices foi Xapuri (Q1 = 7,0 anos, Md = 15 anos, $\mu=19,5$ anos, $\sigma=16,4$ anos, $C_{v}=84 \%$ ). Faixas etárias baixas também foram encontradas nessas duas microrregiões para o período de 1992 a 1997 (Q1 = 12 anos, $\mathrm{Md}=20$ anos para a microrregião de Sena Madureira e Q1 = 12 anos, $\mu=24,9$ anos, $\sigma=17,4$ anos, $C_{v}=69,9 \%$ para a de Brasiléia).

$O$ estudo da escolaridade dos pacientes no estado mostrou que $25,8 \%$ ( $n=1.775)$ deles tinham apenas de 1 a 3 anos de estudo e $22,7 \%$ ( $\mathrm{n}=1.558$ ) possuíam de 4 a 7 anos de estudo. Somando-se esses valores com o índice de não-alfabetizados, constatou-se que $62,2 \%(\mathrm{n}=4.273$ ) dos pacientes tinham sete anos ou menos de estudo. O Vale do Juruá apresentou o maior número de não-alfabetizados $(20,4 \% ; \mathrm{n}=175)$, quando comparado com o Vale do Acre $(12,7 \% ; n=765)$. A microrregião de Tarauacá apresentou o maior número de pacientes não-alfabetizados $(22,4 \%$; $\mathrm{n}=80$ ). Contudo, foi na microrregião de Brasiléia onde houve maior índice de pacientes com 1 a 3 anos de estudo $(32,2 \% ; n=670)$. O Município de Xapuri manifestou a maior freqüência de leishmaniose tegumentar americana entre esses pacientes $(42,6 \% ; n=342)$. Já o Município de Porto Walter teve o maior número de não-alfabetiza$\operatorname{dos}(40 \% ; \mathrm{n}=6)$. 
Figura 1

Prevalência no número de casos de leishmaniose tegumentar americana no Estado do Acre, Brasil, entre 1992 e 1997 e entre 2001 e 2006
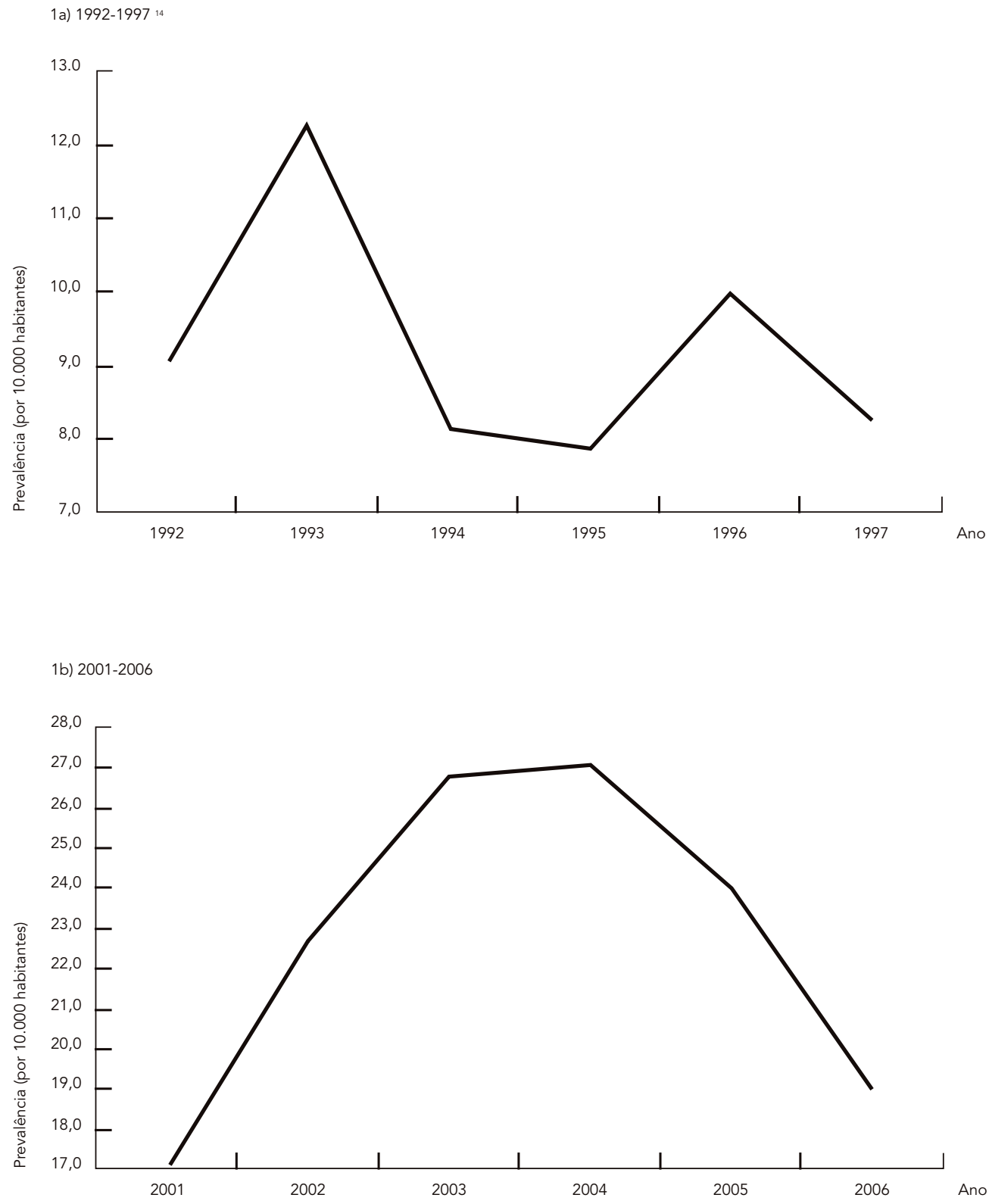

Dos casos notificados no estado entre 2001 e 2006, o correspondente a $62,7 \%$ ( $n=5.036$ ) ocorreu em moradores de zona rural. No Vale do Juruá foram $67,3 \%$ ( $\mathrm{n}=708$ ), valor maior do que o encontrado na outra mesorregião $(62 \%$; $n=$ 4.328). Dentro da mesorregião do Vale do Acre, a microrregião de Rio Branco apresentou o maior número de moradores de zona urbana $(45,6 \%$; $\mathrm{n}=1.634)$ e a de Brasiléia a maior freqüência da zona rural (72,7\%; $\mathrm{n}=1.545)$. Entre os municípios, Epitaciolândia, Senador Guiomard, Rio Branco e Plácido de Castro, tiveram os maiores índices de moradores da zona rural com leishmaniose tegumentar americana $(67,3 \%, \mathrm{n}=259 ; 59,7 \%$, 
Distribuição da prevalência de leishmaniose tegumentar americana por 10 mil habitantes nos períodos de 1992 a 1997 e de 2001 a 2006 , conforme micro e mesorregião do Estado do Acre, Brasil.

\begin{tabular}{|c|c|c|c|c|c|c|c|c|}
\hline & $\begin{array}{l}2001 \\
n(P)\end{array}$ & $\begin{array}{l}2002 \\
n(P)\end{array}$ & $\begin{array}{l}2003 \\
n(P)\end{array}$ & $\begin{array}{l}2004 \\
n(P)\end{array}$ & $\begin{array}{l}2005 \\
n(P)\end{array}$ & $\begin{array}{l}2006 \\
n(P)\end{array}$ & $\begin{array}{c}2001-2006 \\
n(P)\end{array}$ & $\begin{array}{c}1992-1997 \text { * } \\
\text { P }\end{array}$ \\
\hline \multicolumn{9}{|l|}{ Microrregião } \\
\hline Cruzeiro do Sul & $142(13,7)$ & $102(9,5)$ & $113(10,3)$ & $109(9,3)$ & $113(9,3)$ & $63(5,2)$ & $642(52,6)$ & 25,8 \\
\hline Tarauacá & $75(12,7)$ & $81(12,9)$ & $77(12,3)$ & $64(9,0)$ & $59(8,0)$ & $84(11,6)$ & $440(61,0)$ & 38,0 \\
\hline Sena Madureira & $170(48,2)$ & $254(64,4)$ & $208(57,8)$ & $246(59,5)$ & $234(59,5)$ & $192(44,3)$ & $1.304(311,4)$ & 80,4 \\
\hline Rio Branco & $277(8,3)$ & $585(16,7)$ & $740(21,5)$ & $882(23,9)$ & $795(20,6)$ & $558(14,7)$ & $3.837(101,1)$ & 40,6 \\
\hline Brasiléia & $302(67,3)$ & $341(71,6)$ & $441(96,9)$ & $456(93,0)$ & $378(74,4)$ & $375(72,5)$ & $2.293(443,3)$ & 231,8 \\
\hline \multicolumn{9}{|l|}{ Mesorregião } \\
\hline Vale do Acre & $749(18,4)$ & $1.180(27,1)$ & $1.389(32,9)$ & $1.584(34,5)$ & $1.407(29,8)$ & $1.125(23,8)$ & $7.434(158,2)$ & 60,2 \\
\hline Vale do Juruá & $217(13,3)$ & $183(10,7)$ & $190(11,0)$ & $173(9,2)$ & $172(8,8)$ & $147(7,6)$ & $1.082(55,7)$ & 30,3 \\
\hline
\end{tabular}

n: número de casos de leishmaniose; P: prevalência.

* Silva et al. 13

Figura 2

Distribuição da porcentagem dos casos de leishmaniose tegumentar americana no Estado do Acre, Brasil, no período de 2001 a 2006 , conforme a idade dos pacientes.

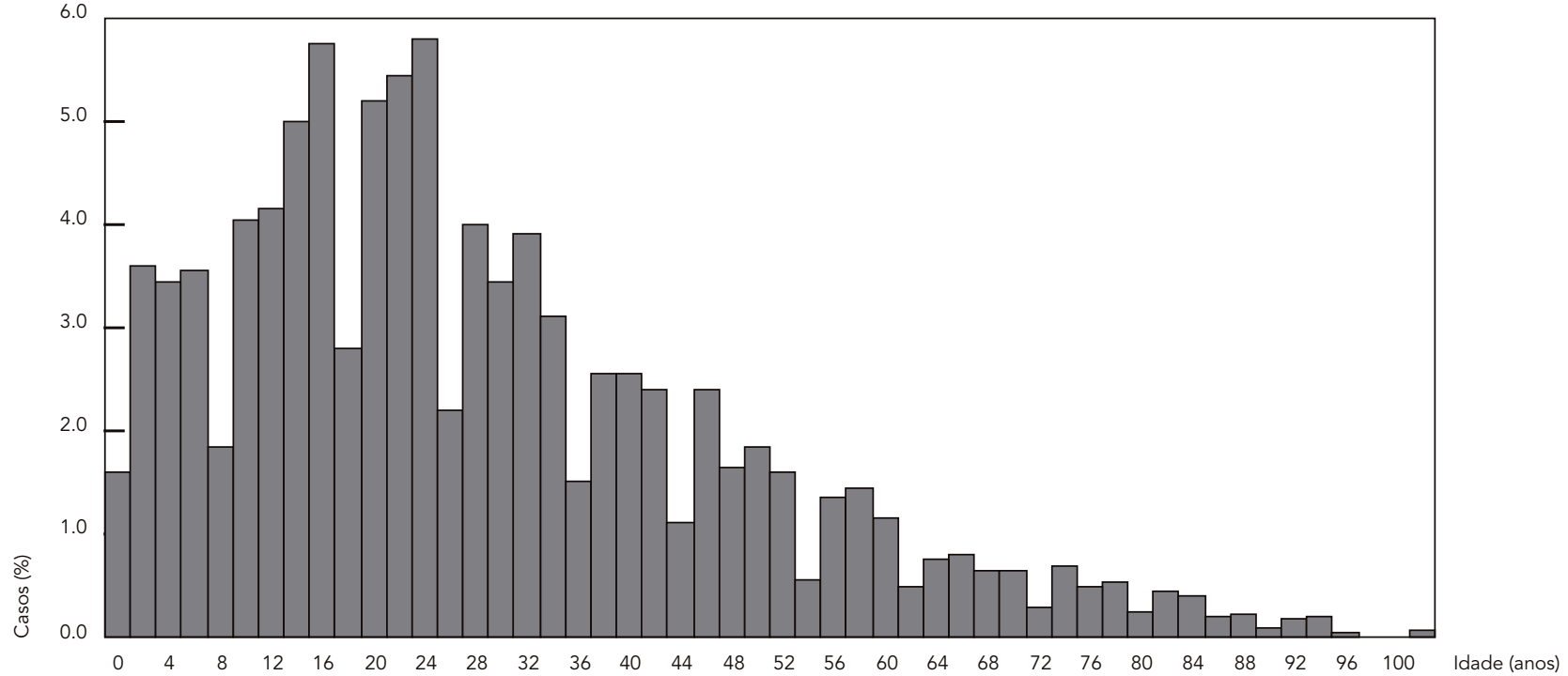

$\mathrm{n}=71 ; 51,4 \%, \mathrm{n}=1.269$ e $46,4 \%, \mathrm{n}=142$, respectivamente).

Observaram-se mudanças em todo estado em relação às ocupações dos pacientes acometidos pela leishmaniose tegumentar americana. Do primeiro período para o segundo, acentuou- se o padrão de maior ocorrência entre populações com ocupações não-rurais e/ou não-determinada. As microrregiões de Tarauacá e de Sena Madureira destacaram-se por apresentar diferenças importantes entre os percentuais nos casos entre as populações rurais nos dois perí- 
odos e conseqüentes elevações nos casos entre aqueles com ocupações não-rurais e não-determinadas (Tabela 2). Entre 2001 e 2006, o município com o menor índice de casos entre as populações rurais foi Bujari $(4,1 \% ; n=2)$, enquanto que Marechal Thaumaturgo apresentou o maior nestas populações $(48,4 \% ; n=45)$. Já Cruzeiro do Sul foi o município com a maior freqüência de casos em populações não-rurais $(54,5 \% ; \mathrm{n}=72)$. Ao passo que Sena Madureira foi a que apresentou o menor índice nessas populações $(10,4 \%$; $\mathrm{n}=38$ ). Nesse último município também houve a maior freqüência em pessoas com ocupação não-determinada (85,3\%; n = 313), em oposição a Porto Walter, onde somente $15,4 \%(n=2)$ dos casos foram em indivíduos com esta ocupação. Ressalta-se que no período de 2001 a 2006 não se obteve dados sobre ocupação em 65,1\% (5.544) do total da população em estudo.

Houve maior realização de diagnóstico feito pelos métodos laboratoriais disponíveis (intradermorreação de Montenegro, exame parasitológico e histopatológico) para os casos no estado (90\%; $\mathrm{n}=7.661)$ quando comparado com o clínico-epidemiológico $(10 \% ; \mathrm{n}=851)$. Salienta-se que para essa variável houve quatro casos sem informação. Esses valores são inversos àqueles apresentados entre 1992 e 1997 no estado, os quais corresponderam a $84 \%$ feitos somente por meio das manifestações clínicas da doença. O maior número de diagnóstico ocorreu no Vale do Acre $(89,1 \% ; n=6.826)$ enquanto no do Juruá foi de $10,9 \%(n=835)$ entre 2001 e 2006. Índices elevados de diagnóstico laboratorial da leishmaniose tegumentar americana ocorreram em todas as microrregiões no primeiro período, mas foram as de Sena Madureira (93,5\%; $\mathrm{n}=1.219)$, Rio Branco (91,9\%; $\mathrm{n}=3.526)$ e Brasiléia $(90,7 \%$; = 2.081) que apresentaram os maiores valores. Já os menores foram nas microrregiões de Tarauacá (83\%; $\mathrm{n}=365)$ e de Cruzeiro do Sul $(73,2 \%$; $\mathrm{n}=$ 470) (Tabela 3).

Entre todos os casos registrados no estado, foram diagnosticadas duas formas de leishmaniose tegumentar americana: cutânea $(75 \%$; $\mathrm{n}=$ $6.386)$ e mucosa $(25 \% ; \mathrm{n}=2.128)$. Para dois indivíduos não havia dados disponíveis sobre a forma clínica. No Vale do Acre a forma cutânea foi de $75 \%$ ( $\mathrm{n}=5.574)$ e a mucosa de $25 \%(\mathrm{n}=1.858)$. As mesmas proporções foram observadas no Vale do Juruá, $75 \%(n=812)$ da forma cutânea e 25\% (n= 270) da mucosa. As microrregiões de Rio Branco $(79,5 \% ; n=3.048)$ e de Cruzeiro do Sul $(78,2 \% ; n=$ 502) tiveram os maiores percentuais da cutânea. Entre 1992 e 1996 essas microrregiões apresentaram $89,6 \%(n=941)$ e $81,9 \%(n=176)$, respectivamente. Entre 2001 e 2006, a forma mucosa foi a de maior ocorrência nas microrregiões de Sena Madureira $(36,5 \%$; $\mathrm{n}=476)$ e de Tarauacá (29,5\%). Enquanto que de 1992 a 1997 a presen-

Percentual de casos de leishmaniose tegumentar americana segundo ocupação nos períodos de 1992 a 1997 e de 2001 a 2006 no Estado do Acre, Brasil, e em cada uma de suas micro e mesorregiões.

\begin{tabular}{|c|c|c|c|c|c|c|c|c|}
\hline & $\begin{array}{c}\text { Ocupações } \\
\text { rurais *** } \\
\%(n)\end{array}$ & $\begin{array}{l}\text { Ocupações } \\
\text { não-rurais \# } \\
\text { \% (n) }\end{array}$ & $\begin{array}{c}\text { Ocupações não- } \\
\text { determinadas \#\# } \\
\text { \% (n) }\end{array}$ & $\begin{array}{l}\text { Total } \\
\% \text { (n) }\end{array}$ & $\begin{array}{c}\text { Ocupações } \\
\text { rurais *** } \\
\%(n)\end{array}$ & $\begin{array}{l}\text { Ocupações } \\
\text { não-rurais \# } \\
\text { \% (n) }\end{array}$ & $\begin{array}{c}\text { Ocupações não- } \\
\text { determinadas \#\# } \\
\qquad \%(n)\end{array}$ & $\begin{array}{l}\text { Total } \\
\%(n)\end{array}$ \\
\hline \multicolumn{9}{|l|}{ Microrregião } \\
\hline Cruzeiro do Sul & $39,4(85)$ & $16,2(35)$ & $44,4(96)$ & $100,0(216)$ & $34,0(92)$ & $44,6(121)$ & $21,4(58)$ & $100,0(271)$ \\
\hline Tarauacá & $41,5(76)$ & $13,1(24)$ & $45,4(83)$ & $100,0(183)$ & $10,3(28)$ & $32,6(89)$ & $57,1(156)$ & $100,0(273)$ \\
\hline Sena Madureira & $38,0(92)$ & $11,2(27)$ & $50,8(123)$ & $100,0(242)$ & $8,6(48)$ & $14,8(83)$ & $76,6(429)$ & $100,0(560)$ \\
\hline Rio Branco & $33,3(348)$ & $25,0(261)$ & 41,7 (437) & $100,0(1.046)$ & $17,0(154)$ & $29,6(268)$ & $53,4(483)$ & 100,0 (905) \\
\hline Brasiléia & $49,2(428)$ & $6,0(52)$ & $44,8(390)$ & $100,0(870)$ & $21,8(210)$ & $25,4(245)$ & $52,8(508)$ & $100,0(963)$ \\
\hline \multicolumn{9}{|l|}{ Mesorregião } \\
\hline Vale do Acre & 40,2 (868) & $15,8(340)$ & 44,0 (950) & $100,0(2.158)$ & $17,0(412)$ & 24,5 (596) & $58,5(1.420)$ & $100,0(2.428)$ \\
\hline Vale do Juruá & $40,3(161)$ & $14,8(59)$ & 44,9 (179) & 100,0 (399) & $22,1(120)$ & $38,6(210)$ & $39,3(214)$ & $100,0(544)$ \\
\hline Estado & $40,2(1.029)$ & 15,6 (399) & $44,2(1.129)$ & $100,0(2.557)$ & $17,9(532)$ & $27,1(806)$ & $55,0(1.634)$ & $100,0(2.972)$ \\
\hline
\end{tabular}

\footnotetext{
* Silva et al. 13

** Para o período entre 2001 e 2006 houve 5.544 registros sem informação quanto à ocupação dos indivíduos;

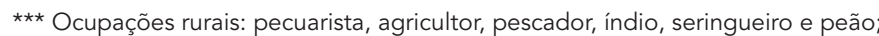

\# Ocupações não-rurais: médico, enfermeiro, funcionário público, militar, engenheiro, entre outras;

\#\# Ocupações não-determinadas: doméstica, aposentado, menor de idade e estudante.
} 
Percentual de casos de leishmaniose tegumentar americana segundo ocupação nos períodos de 1992 a 1997 e de 2001 a 2006 no Estado do Acre, Brasil, e em cada uma de suas micro e mesorregiões.

\begin{tabular}{|c|c|c|c|c|c|c|c|}
\hline \multirow[t]{3}{*}{ Região } & \multicolumn{2}{|c|}{ IDRM } & \multicolumn{2}{|c|}{ Exame parasitológico } & \multicolumn{3}{|c|}{ Exame histológico } \\
\hline & Realizados & Positividade * & Realizados & Positividade * & Realizados & $\begin{array}{l}\text { Visualização de } \\
\text { de Leishmania }\end{array}$ & $\begin{array}{c}\text { Compatível } \\
\text { histologicamente } \\
\text { com leishmaniose }\end{array}$ \\
\hline & $\%(n)$ & $\%(n)$ & $\%(n)$ & $\%(n)$ & $\%(n)$ & $\%(n)$ & $\%(n)$ \\
\hline \multicolumn{8}{|l|}{ Microrregião } \\
\hline Cruzeiro do Sul & $53,7(345)$ & $93,9(324)$ & $63,4(407)$ & $95,8(390)$ & $19,8(127)$ & $48,8(62)$ & $38,6(49)$ \\
\hline Tarauacá & $68,0(299)$ & $97,3(291)$ & $36,6(161)$ & $58,4(94)$ & $9,3(41)$ & $41,5(17)$ & $17,1(7)$ \\
\hline Sena Madureira & $62,1(810)$ & 94,9 (769) & $38,3(499)$ & $89,0(444)$ & $9,4(123)$ & $22,0(27)$ & $18,7(23)$ \\
\hline Rio Branco & $80,4(3.084)$ & $94,6(2.918)$ & $50,7(1.947)$ & $70,0(1.362)$ & $10,9(418)$ & $49,0(205)$ & $21,3(89)$ \\
\hline Brasiléia & $64,9(1.489)$ & $96,0(1.426)$ & $35,5(815)$ & $80,1(653)$ & $16,2(372)$ & $27,4(102)$ & $64,0(238)$ \\
\hline \multicolumn{8}{|l|}{ Mesorregião } \\
\hline Vale do Acre & $72,4(5.383)$ & $95,0(5.113)$ & $43,9(3.261)$ & 75,4 (2.459) & $12,3(913)$ & $36,6(334)$ & $38,3(350)$ \\
\hline Vale do Juruá & $59,5(644)$ & $95,5(615)$ & $52,5(568)$ & $85,2(484)$ & $1,6(168)$ & $47,0(79)$ & $33,3(56)$ \\
\hline Estado & 70,8 (6.027) & $95,0(5.728)$ & 45,0 (3.829) & $76,9(2.943)$ & $12,7(1.081)$ & $38,2(413)$ & $37,6(406)$ \\
\hline
\end{tabular}

IDRM: Intradermorreação de Montenegro.

* Positividade dos respectivos métodos laboratoriais dos exames realizados em cada região.

ça de lesões em mucosas dos pacientes ocorreu em $60,1 \%(n=110)$ dos casos na microrregião de Tarauacá e em 20,7\% ( $n=50)$ dos casos. No segundo período, o Município de Acrelândia teve a maior freqüência de leishmaniose tegumentar americana cutânea $(93,7 \% ; n=149)$. O Município de Porto Walter, que no primeiro período tinha $100 \%$ de seus casos como sendo de cutânea, no segundo passou a apresentar $33,7 \%(n=7)$ da forma mucosa. Os municípios de Capixaba, Mâncio Lima, Porto Acre, Senador Guiomard e Xapuri, que entre os anos de 1992 e 1997 possuíam mais de $90 \%$ de seus casos na forma cutânea, no período de 2001 a 2006 estes valores passaram para $71,6 \%(\mathrm{n}=156) ; 86,3 \%(\mathrm{n}=82) ; 77,3 \%(\mathrm{n}=221)$; $80 \%(n=96)$ e $71,3 \%(n=643)$, respectivamente.

No Brasil, o medicamento de primeira escolha para o tratamento da leishmaniose tegumentar americana é o antimoniato-N-metilglucamina na dose de 10 a $20 \mathrm{mg} \mathrm{Sbv/Kg/d}$, por 20 dias para a forma cutânea, e de $20 \mathrm{mg} \mathrm{Sb} / \mathrm{Kg} / \mathrm{d}$, durante 30 dias, para a forma mucosa, até o máximo de três ampolas por dose (cada ampola contém $5 \mathrm{~mL}$, com $81 \mathrm{mg} \mathrm{Svv} / \mathrm{ml}$ ) 15. No Estado do Acre, entre 2001 e 2006, foi utilizada uma média de 47,2 ampolas por paciente, mediana de 40 ampolas, desvio padrão igual a 26,3 ampolas, coeficiente de variação de 55,7\%, mínimo de zero e máximo de 601 ampolas por indivíduo. O Vale do Acre apresentou a maior média de ampolas por paciente $(\mathrm{Q} 1=30$ ampolas; $\mathrm{Md}=40 ; \mathrm{Q} 3=60 ; \mu=$
48,3; $\sigma=26,7$ ampolas; $C_{v}=55,3 \%$ ) do que o Vale do Juruá (Q1 = 20 ampolas; $\mathrm{Md}=40 ; \mathrm{Q} 3=60 ; \mu=$ 39,6; $\sigma=21,8$ ampolas; $C_{v}=55,1 \%$ ). Na primeira mesorregião, em 18,8\% ( $\mathrm{n}=1.345)$ dos pacientes utilizaram-se 20 ampolas, em 27,8\% ( $\mathrm{n}=1.989)$ aplicaram-se 60 e em 11,8\% ( $n=844) 90$ ampolas. A microrregião que apresentou a menor média de ampolas por paciente foi a de Cruzeiro do Sul (Q1 = 20 ampolas; $\mathrm{Md}=40 ; \mathrm{Q} 3=50 ; \mu=38,6 ; \sigma=$ 20,9 ampolas; $C_{\nu}=54,1 \%$ ) e de Rio Branco obteve a maior média $(\mathrm{Q} 1=40$ ampolas; $\mathrm{Md}=50 ; \mathrm{Q} 3=$ $60 ; \mu=52,1 ; \sigma=26,5$ ampolas; $C_{\nu}=50,8 \%$ ). O Município de Marechal Thaumaturgo destacou-se por apresentar $49,7 \%(n=73)$ de seus pacientes submetidos ao tratamento com apenas 20 ampolas, e Xapuri veio em seguida com $43,6 \%$ de seus pacientes usando 20 ampolas para o tratamento da leishmaniose tegumentar americana.

A recidiva da leishmaniose tegumentar americana ocorreu em 7,6\% $(n=650)$ dos pacientes tratados no estado. A mesorregião do Vale do Juruá apresentou 16,3\%; $n=106$ de recidiva e o Vale do Acre obteve 83,7\%; $\mathrm{n}=544$. No Município de Porto Walter não existiu recidiva no período de 2001 a 2006.

A avaliação do tempo que os pacientes levaram para procurar o diagnóstico mostrou grande variabilidade, apresentando indivíduos que levaram menos de um dia até 62 anos para procurar ajuda médica. No estado, o tempo médio para procurar diagnóstico foi de 6,9 meses, primeiro 
quartil igual a zero, mediana igual a 0,03 mês, terceiro quartil de 1,6 mês, desvio padrão de 24,7 meses e coeficiente de variação de $633 \%$. Tanto na mesorregião do Vale do Acre quanto no Vale do Juruá, houve grandes variabilidades dos valores em torno da média $(\mathrm{Q} 1=0,0$ mês; $\mathrm{Md}=0,03$ mês; Q3 = 1,4 mês; $\mu=3,9$ meses; $\sigma=25,7$ meses; $C_{\nu}=659 \%$ para o Vale do Acre e Q1 = 0,0 mês; $\mathrm{Md}=$ 0,3 mês; Q3 $=2,7$ meses; $\mu=3,8$ meses; $\sigma=16,7$ meses; $C_{v}=439$ para o Vale do Juruá). Entre os anos de 1992 e 1997, nas duas mesorregiões as médias do tempo eram maiores, bem como os valores dos quartis avaliados $(\mathrm{Q} 1=1,03$ mês; Q3 = 6,07 meses; $\mu=7,66$ meses; $\sigma=20,11$ meses; $C_{v}=$ 205,5\% para oVale do Acre e Q1 = 2,03 meses; Q3 = 9,43; $\mu=10,4$ meses; $\sigma=21,3$ meses; $C_{\nu}=205,5 \%$ para o Vale do Juruá). A microrregião de Sena Madureira apresentou a maior média de tempo para procurar tratamento $(\mathrm{Q} 1=0,0$ mês; $\mathrm{Md}=0,8$ mês; $\mathrm{Q} 3=2,7$ meses; $\mu=6,5$ meses; $\sigma=24,9$ meses; $C_{\nu}=$ $383 \%)$ e a de Tarauacá a menor média $(\mathrm{Q} 1=0,0$ mês; $\mathrm{Md}=0,7$ mês; $\mathrm{Q} 3=0,3$ mês; $\mu=0,9$ mês; $\sigma=$ 3,9 meses; $\left.C_{\nu}=433 \%\right)$. No período de 1992 a 1997 , na região de Sena Madureira, 50\% dos pacientes levaram de dois a treze meses para procurar tratamento $(\mathrm{Q} 1=$ 2,03 meses e Q3 = 13,17 meses). O Município de Sena Madureira, pertencente à microrregião de Sena Madureira, apresentou a maior média de tempo para procurar o diagnóstico de leishmaniose tegumentar americana $(\mathrm{Q} 1=$ 0,0 mês; Md = 0,9 mês; Q3 = 3,0 meses; $\mu=7,1$ meses; $\sigma=25,8$ meses; $C_{v}=363 \%$ ) e o Município de Rodrigues Alves, pertencente à microrregião de Cruzeiro do Sul, a menor média $(\mathrm{Q} 1=0,0$ mês; $\mathrm{Md}=0,0$ mês; Q3 = 0,008 mês; $\mu=0,2$ mês; $\sigma=0,9$ mês; $C_{v}=450 \%$ ).

A evolução da doença no estado entre 2001 e 2006 teve índice de 91,5\% ( $\mathrm{n}=7.788)$ de cura, abandono do tratamento de $2,6 \%(\mathrm{n}=222)$, óbito de $0,1 \%(n=7)$, transferência para outro estado de $0,8 \%(n=67)$ e em $5,1 \%(n=432)$ dos indivíduos não havia informações referentes à evolução da doença. Na mesorregião do Vale do Juruá o índice de cura foi de 95,8\% ( $\mathrm{n}=947)$ e de abandono de $3,7 \%$ ( $n=37)$. Já no Vale do Acre o índice de cura foi de $94,9 \%(n=6.841)$ e de abandono de $2,6 \%(n=185)$. A microrregião de Sena Madureira apresentou a maior freqüência de abandono $(4,7 \% ; \mathrm{n}=60)$ e a de Rio Branco o menor $(1,9 \%$; $\mathrm{n}=70$ ). Os municípios de Mâncio Lima e Manoel Urbano tiveram os maiores índices de abandono $(15,8 \%, n=15$ e $15,1 \%, n=31$, respectivamente). Entretanto, o Município de Acrelândia não teve nenhum caso de abandono do tratamento.

\section{Discussão}

A prevalência da leishmaniose tegumentar americana no Estado do Acre mostra que entre os dois estudos, aquele entre 1992 e 199713 e este entre 2001 e 2006, com quatro anos de intervalo entre ambos, há considerável elevação de seus valores. Isso pode advir do real aumento do número de casos novos ou até mesmo da melhoria do sistema de notificação no estado. No entanto, observa-se que o comportamento da prevalência da leishmaniose tegumentar americana no estado no primeiro período é bastante diferente em relação ao segundo. Grandes oscilações dos casos foram bem maiores entre $1992 \mathrm{e}$ 1997. Enquanto no segundo período houve forte tendência ao crescimento linear dos casos até o ano de 2004, quando, por motivos não avaliados, aconteceu queda acentuada da prevalência até o ano de 2006. A característica de crescimento do número de casos com pequenos períodos de flutuação foram também evidenciados no resto do Brasil entre os anos de 1980 e 1999 16. Regiões do estado, como o Município de Xapuri, que ainda permanecem como principais focos da leishmaniose tegumentar americana mereceriam atenção especial por órgãos de saúde locais para combater essa zoonose.

O processo de domicialização de flebotomíneos, como conseqüência direta da alteração no meio ambiente provocada pelo homem 10 , tem levado a um novo padrão na transmissão da leishmaniose tegumentar americana. Populações que teoricamente teriam menor risco para aquisição da doença vêm apresentando crescentes índices de notificação. Verificou-se neste estudo que as mulheres estão cada vez mais sujeitas à aquisição da doença, quando se comparam os dois momentos do estudo. Populações cada vez mais jovens também estão em maior risco de adquirir a leishmaniose em todo o Acre, como também observado no Estado do Paraná 17,18, embora se verifique considerável coeficiente de variação nas idades dos portadores de leishmaniose tegumentar americana. Outra constatação é a elevada freqüência de pacientes moradores em zonas urbanas, como os casos da microrregião de Rio Branco, bem como a evidência de maior e crescente ocorrência da leishmaniose em pessoas com ocupações não-rurais ou nãodeterminadas em todo o estado, principalmente a situação vista nas microrregiões de Tarauacá e de Sena Madureira, entre os dois períodos. Essas novas características do comportamento epidemiológico da leishmaniose tegumentar americana devem apontar para um novo e preocupante modelo de transmissão da doença no estado: a possível aquisição da leishmaniose 
no peridomiciliar ou intradomiciliar. Mulheres, crianças, moradores de zona urbana e indivíduos com ocupações que não necessariamente exigem a entrada na floresta para adquirirem a doença com mais freqüência sugerem essa possibilidade, assim como proposto também em outros estudos 4,5,6,7. Garcia et al. 19, utilizando técnicas de biologia molecular, constataram o risco de aquisição de leishmaniose tegumentar americana no peridomicílio ao coletar flebotomíneos infectados com Leishmania ao redor das residências de moradores da Amazônia boliviana. Contudo, Castro et al. 20, ao avaliar em 332 casos de leishmaniose tegumentar americana no Estado do Paraná, contestem a relação entre crianças menores e mulheres e a transmissão intradomiciliar. Entretanto, Ampuero et al. 1, a partir do acompanhamento de crianças entre 0 e 5 anos em um município do Estado da Bahia, argumentam que crianças com lesões acima da cintura pélvica sugerem aquisição da doença no intra ou peridomicílio.

O elevado índice de indivíduos com baixo nível de escolaridade visto em todo Estado do Acre acometidos pela leishmaniose tegumentar sugere que esta seja uma doença que acomete preferencialmente pessoas de baixo nível sócioeconômico. Essa característica também foi proposta por Passos et al. 21 na região metropolitana de Belo Horizonte, no Estado de Minas Gerais.

A importante mudança no critério de diagnóstico de leishmaniose tegumentar americana observada no estado aventa a possibilidade de considerável melhoria no sistema de diagnóstico entre os períodos de 1992 a 1997 e de 2001 a 2006. Mesmo municípios distantes da capital do Acre, como Rodrigues Alves e Mâncio Lima, apresentaram elevados percentuais de diagnóstico feito por um dos métodos laboratoriais disponíveis no estado. Entretanto, verificou-se que em 70,8\% dos casos no estado o diagnóstico foi efetuado pela IDRM. Essa técnica, por detectar a presença de hipersensibilidade tardia, não consegue diferenciar doença atual de anterior, podendo permanecer positiva mesmo após o correto tratamento 15 . Outro questionamento que se faz em relação a essa técnica é a possibilidade de positividade do teste em outras doenças, como esporotricose 22 . Além desses fatores, o índice de positividade da IDRM no Estado do Acre, tanto no Vale do Acre quanto no Vale do Juruá, foi inferior ao relatado na literatura 23,24 . O que aponta para a possibilidade de que, apesar da possível melhora no sistema laboratorial de diagnóstico da leishmaniose tegumentar americana, possa haver falhas técnicas em alguma fase da realização do teste. Tojal et al. 25, conduzindo trabalho sobre leishmaniose tegumentar americana na cidade de Rio Branco em 2002 sob condições técnicas rigorosas, encontraram positividade de 98\% da IDRM. Esse teste constitui-se, portanto, em excelente auxiliar do diagnóstico clínico da doença, mas não como única ferramenta para este fim. Logo, tem sua devida importância em certos contextos epidemiológicos 26 .

O índice de positividade no exame parasitológico nas duas mesorregiões do estado também foi inferior ao apresentado em outros estudos 25,27. Entretanto, ressalta-se favoravelmente a manutenção da microrregião de Cruzeiro do Sul como sendo aquela com maior ocorrência de exame parasitológico positivo, e desfavoravelmente a microrregião de Tarauacá, que teve o menor índice de exame parasitológico positivo, o que pode estar diretamente relacionado com o fato de ter apresentado a maior ocorrência de exame não-realizado. Esses dois resultados dessa microrregião podem estar intimamente inter-relacionados, pois quanto mais experiência o examinador possui maior será a acurácia do exame.

O exame histopatológico no estado mostrou índice de positividade inferior ao de publicações anteriores 23,25. Entretanto, a microrregião de Rio Branco destacou-se por apresentar a maior freqüência de exame histológico positivo.

Diagnósticos por meio de biologia molecular, como a reação em cadeia da polimerase (PCR) ainda são onerosos e restritos a trabalhos científicos, apesar das irrefutáveis demonstrações das vantagens de suas sensibilidade e especificidade 28,29,30,31. Tojal et al. 25, utilizando PCR mKDNA, encontraram $100 \%$ de positividade entre 50 pacientes da cidade de Rio Branco.

A existência de alguns municípios com franca expansão da forma mucosa da leishmaniose tegumentar americana nos dois períodos aponta para a necessidade de estudos locais acerca das potenciais razões para que isto ocorra, tendo em vista ser a forma mucosa a que pode causar graves lesões e provoca prejuízos ao indivíduo tanto psicológicos quanto sociais e econômicos. Felizmente, a forma cutânea ainda é a mais prevalente no estado, como visto também em outras regiões do Brasil 4,5,21.

A quantidade de ampolas de antimoniato-Nmetilglucamina por paciente no estado aquém do esperado pode sugerir tratamento inadequado por erro na posologia ou por abandono de tratamento. Entretanto, o registro da grande quantidade de pacientes mais jovens com leishmaniose tegumentar americana, os quais usariam menos de três ampolas do medicamento por dia, pode ter desviado a média de ampolas por paciente para baixo. O tratamento inadequado poderia também justificar o menor número de curas verificado em alguns municípios. 
O sucesso do tratamento, além da adesão do paciente, estão diretamente relacionados ao tempo que o paciente leva para procurar o diagnóstico ${ }^{32}$. Percentuais diferentes de recidiva no Município de Cruzeiro do Sul em relação ao resto do estado podem estar vinculados ao maior tempo para procurar tratamento, devido à possibilidade de menor resposta ao tratamento dos pacientes com maior tempo de convívio com a doença. O tempo para procura de tratamento no Acre foi maior do que em outros locais 1,20, apesar de os resultados terem mostrado grandes oscilações no coeficiente de variação do tempo de procurar por ajuda médica. Esse elevado tempo também poderia contribuir com o aumento das formas mucosas de leishmaniose tegumentar americana no estado.

\section{Resumo}

Efetuou-se estudo estatístico descritivo em 8.516 casos de leishmaniose tegumentar americana no Estado do Acre, Brasil, no período de 2001 a 2006 (segundo período), comparando-se com os resultados de publicação anterior com dados no mesmo estado entre 1992 e 1997 (primeiro período). A prevalência no estado mais que dobrou entre os dois momentos (55,7/10 mil habitantes de 1992 a 1997 e 128,5/10 mil habitantes entre 2001 e 2006. O sexo masculino foi o mais acometido $(68,8 \%$, $n=5.860$ ) no segundo período. A média das idades foi de 26,3 anos, valor discretamente menor do que o do primeiro período. Pacientes com baixa escolaridade foram os mais acometidos pela doença. As demais variáveis avaliadas foram zona de residência, ocupação, critério de diagnóstico, forma clínica, tratamento, recidiva, tempo para procurar tratamento e evolução da doença. Conclui-se que houve piora nos indicadores epidemiológicos da leishmaniose tegumentar americana avaliados no estado entre os períodos estudados.

Leishmaniose; Distribuição Espacial da População; Ecossistema Amazônico
Como conclusão, verifica-se, de forma geral, piora dos indicadores epidemiológicos da leishmaniose tegumentar americana avaliados no estado entre os períodos estudados. A melhora desse quadro pode ser possível por meio do diagnóstico e tratamento adequados e precoces dos pacientes, controle dos hospedeiros reservatórios e dos vetores no peridomicílio e intradomicílio, e uso de medidas individuais de proteção (quase sempre inacessível à população sob maior risco 3 ). Contudo, o melhor nível de conhecimento sobre a leishmaniose tegumentar americana pelas populações das áreas endêmicas pode ser uma importante ferramenta para o sucesso dessas medidas, como sugerido por outros autores 33 .

\section{Colaboradores}

N. S. Silva realizou o planejamento do trabalho, o estudo estatístico, a redação e revisão do artigo. V. D. Muniz coletou os dados e revisou o artigo.

\section{Agradecimentos}

À senhora Maria Carmelinda Gonçalves Pinto, do Departamento de Ações Básicas em Saúde (DABS) do Acre, pelo acesso às informações sobre a leishmaniose tegumentar no Estado do Acre. Ao Prof. Dr. José Antônio Cordeiro, da Faculdade de Medicina de São José do Rio Preto, pelo relevante auxílio nas correções estatísticas. 


\section{Referências}

1. Ampuero J, Macêdo V, Marsden P. Características clínicas da leishmaniose tegumentar em crianças de 0 a 5 anos em uma área endêmica de Leishmania (Viannia) braziliensis. Rev Soc Bras Med Trop 2006; 39:22-6.

2. Martins LM, Rebêlo JMM, Santos MCFV, Costa JML, Silva AR, Ferreira LA. Ecoepidemiologia da leishmaniose tegumentar no Município de Buriticupu, Amazônia do Maranhão, Brasil, 1996 a 1998. Cad Saúde Pública 2004; 20:735-43.

3. Santos JB, Lauand L, Souza GS, Macêdo VO. Fatores sócio-econômicos e atitudes em relação à prevenção domiciliar da leishmaniose tegumentar americana, em uma área endêmica do Sul da Bahia, Brasil. Cad Saúde Pública 2000; 16:701-8.

4. Secretaria de Estado de Saúde de São Paulo, Superintendência de Controle de Endemias (Sucen), Taubaté. Aspectos epidemiológicos da leishmaniose tegumentar americana no Município de Ubatuba, litoral de São Paulo, Brasil, 1993-2003. Rev Saúde Pública 2004; 38:331-2.

5. Follador I, Araujo C, Cardoso MA, Tavares-Neto J, Barral A, Miranda JC, et al. Surto de leishmaniose tegumentar americana em Canoa, Santo Amaro, Bahia, Brasil. Rev Soc Bras Med Trop 1999; 32: 497-503.

6. Nunes AG, Paula EV, Teodoro R, Prata A, Silva-Vergara ML. Aspectos epidemiológicos da leishmaniose tegumentar americana em Varzelândia, Minas Gerais, Brasil. Cad Saúde Pública 2006; 22:1343-7.

7. Guerra JAO, Ribeiro JAS, Coelho LIARC, Barbosa MGV, Paes MG. Epidemiologia de leishmaniose tegumentar na Comunidade São João, Manaus, Amazonas, Brasil. Cad Saúde Pública 2006; 22:2319-27.

8. Aparicio C, Bitencourt MD. Modelagem espacial de zonas de risco da leishmaniose tegumentar americana. Rev Saúde Pública 2004; 38:511-6.

9. Lessa MM, Lessa HA, Castro TWN, Oliveira A, Scherifer A, Machado P, et al. Leishmaniose mucosa: aspectos clínicos e epidemiológicos. Rev Bras Otorrinolaringol 2007; 73:843-7.

10. Costa-Simone M, Cechinel M, Bandeira V, Zannuncio JC, Lainson R, Rangel EF. Lutzomyia (Nyssomyia) whitmani s.I. (Antunes \& Coutinho, 1939) (Diptera: Psychodidae: Phlebotominae): geographical distribution and the epidemiology of American cutaneous leishmaniasis in Brazil - mini-review. Mem Inst Oswaldo Cruz 2007; 102:149-53.

11. Ximenes MFFM, Silva VPM, Queiroz PVS, Rego MM, Cortez AM, Batista LMM, et al. Flebotomíneos (Diptera: Psychodidae) e leishmanioses no Rio Grande do Norte, Nordeste do Brasil - reflexos do ambiente antrópico. Neotrop Entomol 2007; 36:128-37.

12. Da Silvia LMR, Cunha PR. A urbanização da leishmaniose tegumentar americana no Município de Campinas - São Paulo (SP) e região: magnitude do problema e desafios. An Bras Dermatol 2007; 82:515-9.

13. Silva NS, Viana AB, Cordeiro JA, Cavasini CE Leishmaniose tegumentar americana no Estado do Acre, Brasil. Rev Saúde Pública 1999; 33:554-9.
14. Divisão de Pesquisa do Estado do Acre, Instituto Brasileiro de Geografia e Estatística. Anuário estatístico do Acre. Rio Branco: Instituto Brasileiro de Geografia e Estatística; 1997.

15. Secretaria de Vigilância em Saúde, Ministério da Saúde. Manual de vigilância da leishmaniose tegumentar americana. 2a Ed. Brasília: Ministério da Saúde; 2007.

16. Gontijo B, Carvalho MLR. Leishmaniose tegumentar americana. Rev Soc Bras Med Trop 2003; 36: 71-80.

17. Monteiro WM, Neitzke HC, Lonardoni MVC, Silveira TGV, Ferreira MEMC, Teodoro U. Distribuição geográfica e características epidemiológicas da leishmaniose tegumentar americana em áreas de colonização antiga do Estado do Paraná, Sul do Brasil. Cad Saúde Pública 2008; 24:1291-303.

18. Lima MVN, Oliveira RZ, Lima AP, Felix MLO, Silveira TGV, Rossi RM, et al. Atendimento de pacientes com leishmaniose tegumentar americana: avaliação nos serviços de saúde de municípios do noroeste do Estado do Paraná, Brasil. Cad Saúde Pública 2008; 23:2938-48.

19. Garcia AL, Tellez T, Parradoa R, Rojasa E, Bermudez $\mathrm{H}$, Dujardinb JC. Epidemiological monitoring of American tegumentary leishmaniasis: molecular characterization of a peridomestic transmission cycle in the Amazonian lowlands of Bolivia. Trans R Soc Trop Med Hyg 2007; 101:1208-13.

20. Castro EA, Soccol VT, Membrive N, Luz E. Estudo das características epidemiológicas e clínicas de 332 casos de leishmaniose tegumentar notificados na região norte do Estado do Paraná de 1993 a 1998. Rev Soc Bras Med Trop 2002; 35:445-52.

21. Passos VMA, Barreto SM, Romanha AJ, Krettii AU, Volpini AC, Gontijo CMF, et al. Leishmaniose tegumentar na região metropolitana de Belo Horizonte: aspectos clínicos, laboratoriais, terapêuticos e evolutivos (1989-1995). Rev Soc Bras Med Trop 2001; 34:5-12.

22. De Lima-Barros MB, Schubach A, Francesconi-doValle AC, Gutierrez-Galhardo MC, Schubach TM, Conceição-Silva F, et al. Positive Montenegro skin test among patients with sporotrichosis in Rio de Janeiro. Acta Trop 2005; 93:41-7.

23. Vera LA, Santos JB, Macêdo VO, Magalhães AV, Ciuffo IA, Santos CG. Avaliação da influência da infecção bacteriana secundária na evolução da leishmaniose cutânea em Corte de Pedra, Bahia. Rev Soc Bras Med Trop 2001; 34:233-7.

24. Shaw JJ, Lainson R. Leishmaniasis in Brazil: some observations on intradermal reactions to different trypanosomatid antigens of patients suffering from cutaneous and mucocutaneous leishmaniasis. Trans R Soc Trop Med Hyg 1975; 69:323-35.

25. Tojal AC, Cupolillo E, Volpini AC, Almeida R, Romero GAS. Species diversity causing human cutaneous leishmaniasis in Rio Branco, state of Acre, Brazil. Trop Med Int Health 2006; 11:1388-98.

26. Borges VC, Ruiz MCM, Gomes PM, Colombo AR, Silva LA, Romero HD, et al. Intradermorreação de Montenegro após sucessivas repetições do teste em Porteirinha, MG. Rev Soc Bras Med Trop 2002; 36:249-51. 
27. Guerra JA, Talhari S, Paes MG, Garrido M, Talhari JM. Aspectos clínicos e diagnósticos da leishmaniose tegumentar americana em militares simultaneamente expostos à infecção na Amazônia. Rev Soc Bras Med Trop 2003; 36:587-90.

28. Rodrigues EH, Brito MEF, Mendonça MG Werkhäuser RP, Coutinho EM, Souza WV, et al. Evaluation of PCR for diagnosis of American cutaneous leishmaniasis in an area of endemicity in northeastern Brazil. J Clin Microbiol 2002; 40:3572-6.

29. Oliveira JG, Novai FO, De Oliveira CI, Da Cruz Junior AC, Campos LF, Da Rocha AV, et al. Polymerase chain reaction (PCR) is highly sensitive for diagnosis of mucosal leishmaniasis. Acta Trop 2005; 94:55-9.

30. Rhajaoui M, Nasereddin A, Fellah H, Azmi K, Amarir F, Al-Jawabreh A, et al. New clinicoepidemiologic profile of cutaneous leishmaniasis, Morocco. Emerg Infect Dis 2007; 13:1358-60.
31. Lessa MM, Lessa HAL, Castro TWN, Oliveira A, Scherifer A, Machado P, et al. Mucosal leishmaniasis: epidemiological and clinical aspects. Rev Bras Otorrinolaringol 2007; 73:843-7.

32. Passos VMA, Barreto SM, Romanha AJ, Krettii AU, Volpini AC, Costa MFFL. American cutaneous leishmaniasis: use of a skin test as a predictor of relapse after treatment. Bull World Health Organ 2000; 78:968-74.

33. Moreira RCR, Rebêlo JMM, Gama MEA, Costa JML. Nível de conhecimento sobre Leishmaniose Tegumentar Americana (LTA) e uso de terapias alternativas por populações de uma área endêmica da Amazônia do Maranhão, Brasil. Cad Saúde Pública 2002; 18:187-95.

Recebido em 17/Abr/2008

Versão final reapresentada em 07/Jan/2009 Aprovado em 21/Jan/2009 